\title{
A room with a view: a special issue with a special perspective
}

\author{
Simone Borghesi (D) \\ European University Institute and University of Siena, Florence, Italy \\ Corresponding author. E-mail: simone.borghesi@unisi.it
}

(Submitted 02 March 2021; revised 08 March 2021; accepted 14 March 2021)

\begin{abstract}
The present article describes the main insights deriving from the papers collected in this special issue which jointly provide a 'room with a view' on some of the most relevant issues in climate policy such as: the role of uncertainty, the distributional implications of climate change, the drivers and applications of decarbonizing innovation, the role of emissions trading and its interactions with companion policies. While looking at different issues and from different angles, all papers share a similar attention to policy aspects and implications, especially in developing countries. This is particularly important to evaluate whether and to what extent the climate policies adopted thus far in developed countries can be replicated in emerging economies.
\end{abstract}

Keywords: climate change; developing countries; distribution; emissions trading; innovation; uncertainty JEL classification: D81; H23; Q54; Q55; Q56

\section{Introduction}

Climate change poses serious and ever-increasing threats to mankind. Many scientists and institutions have repeatedly warned governments that the world is at a crossroads: climate action is urgent and the window of opportunity to keep temperature increases within the limits of the Paris Agreement (PA) is rapidly closing (Rogelj et al., 2016, 2018; Arneth et al., 2019).

While shifting the focus of public opinion on the dramatic consequences of the ongoing health crisis, the pandemic of COVID-19 has not diminished the need to fight climate change. On the contrary, it has probably enlarged our view on the possible (and somehow unexpected) interactions between environmental degradation and health consequences.

In response to the urgent call for climate action, many jurisdictions have adopted more ambitious emissions reduction targets as required by the ratcheting-up mechanism of the PA. Several jurisdictions (Europe, UK, California, New Zealand) aim at achieving climate neutrality by 2050, and China intends to achieve such an ambitious target by 2060. These promising commitments made by some early movers need to be followed 
by rapid action in other jurisdictions as well, developing countries included, if we are to halt - or at least slow down - climate change.

To get a deeper understanding on the challenges posed by the ongoing climate change and on the implications of some of the policies that have been adopted to address them, this special issue collects selected papers from keynote speakers and organizers of past editions of the Florence School of Regulation Annual Climate Conference. Based at the European University Institute (EUI) in Florence and organized by the Climate research area of the Florence School of Regulation since 2015, the conference offers an inspiring broad view to its participants, both literally and metaphorically.

Literally, since from the EUI premises participants can enjoy a splendid view of the surrounding Tuscan hills, and of the Brunelleschi dome of the Duomo Cathedral downtown. As in the famous movie 'A Room with a View' (1985), coming to Florence becomes a trip into nature and history, into the origins of modern civilization that reinforces the intergenerational perspective that is needed to look at environmental problems.

Metaphorically, the conference offers its participants a broad view on the most urgent environmental problems, on the new issues and emerging trends in the environmental economics research, and on the hottest topics in climate policy.

The conference covers the main existing climate-related policies in four areas: (1) energy and carbon taxes, (2) emissions trading, (3) energy efficiency measures and (4) renewable energy policies.

Each one of the five papers collected in this special issue contributes to a deeper understanding in one (or more) of these areas. Moreover, while looking at different issues and from different angles, all papers share a similar attention to policy aspects and implications, especially in developing countries. This is particularly important to evaluate whether and to what extent the policies adopted thus far in developed countries to fight climate change can be replicated in emerging economies.

\section{Uncertainty and distributional aspects of climate policies}

The first paper that appears in this special issue, 'Regional climate policy under deep uncertainty: robust control and distributional concerns' by Brock and Xepapadeas (2020), for instance, points out that uncertainties about climate change are amplified by the fact that climate damages differ across the globe, being larger in low latitude (warmer) areas around the Equator. For this reason, they study climate change policies using a regional structure that allows them to analyze the distributional effects of climate on regional carbon taxes. More precisely, they examine climate change policies by developing a regional climate-economy model that considers deep uncertainty associated with: (i) temperature dynamics (climate uncertainty), (ii) regional climate change damages (damage uncertainty) and (iii) climate policy in the form of carbon taxes (policy uncertainty). The conceptual model proposed by the authors enriches the sources of uncertainty examined in the literature, accounting simultaneously for: (i) ambiguity (which arises when the regulator is uncertain on how to weight alternative models), (ii) misspecification (which occurs when the model used is an imperfect approximation of the true one), and (iii) transition risks (which firms face when a climate policy is introduced).

Applying robust control methods, the authors derive optimal emission policies under each source of uncertainty. They show that higher aversion to ambiguity leads to more conservative policies regarding emissions (and, therefore, higher carbon taxes), and that damage uncertainty produces more conservative behaviors than climate uncertainty. 
Moreover, the optimal carbon tax is relatively lower in the Tropics (the most vulnerable/poorest region) than in the other regions of the model when the distributional effects of climate change are taken into account. As underlined by the authors, these results can have relevant implications for future climate policies as they call for non-uniform carbon taxes and differentiated policy instruments among rich and poor countries.

Like Brock and Xepapadeas (2020), Labeaga et al. (2020), in their paper 'Energy taxation, subsidy removal and poverty in Mexico' look at distributional aspects of climate change, performing an empirical analysis focused on poverty in a growing middleincome country, Mexico. Understanding the distributional impacts of energy taxes is particularly important in Mexico as it shows large disparities in energy consumption and high poverty and inequality levels. For this purpose, using a rich dataset on Mexican household incomes and expenditures, the paper investigates the environmental and distributional impacts of the proposed energy tax reforms, and of a hypothetical partial removal of existing electricity subsidies. The authors perform simulations with parameter estimates deriving from a household demand system to analyze the impact of three important reforms in Mexico: the introduction of gasoline taxes in 2014, the suppression of the 2014 gasoline subsidy and the partial elimination of electricity subsidies.

The estimation of the demand system reveals significant differences across Mexican households between those owning and not owning a vehicle. Moreover, simulation results show that various revenue recycling alternatives may generate remarkable savings in energy demand and greenhouse gases while alleviating poverty (including energy and food poverty). Although these results are obviously affected by the country's idiosyncratic features and may not be easily extended to other developing countries, they clearly suggest that increased energy taxation, energy subsidy removal, and proper compensatory mechanisms may generate win-win solutions in terms of energy reforms and poverty mitigation.

\section{Carbon-reducing innovations: theoretical and empirical aspects}

As Labeaga et al. (2020: 18) claim, 'international experience shows that putting energy prices 'right' requires long-term plans and the introduction of mechanisms to accommodate the transition'. However, 'getting the price right' takes time and may not be sufficient to induce carbon-reducing innovation at the scale and speed that are needed. Indeed, recent studies suggest that carbon pricing would need to grow by ten times (or even more) to achieve climate neutrality at minimum cost by mid-century (Burke et al., 2019; Verde et al., 2020). Such an increase, however, might be politically unfeasible: past experience shows that there is an upper bound to the level of carbon prices that most countries and societies are willing to accept. Additional policies are, therefore, needed on top of carbon pricing to promote innovation.

Frank Convery (2021), in his paper 'Carbon-reducing innovation as the essential policy frontier - towards finding the ways that work' contributes to our deeper understanding of the key elements that are necessary to spur innovation. He does so by digging deeper into the experiences of countries that differ in terms of income levels, geographical locations, and institutional features (e.g., US, China, Denmark, Australia). A common lesson emerges from these different contexts: although policy is designed at the local level, 'achieving innovation at scale is, above all, a global enterprise' (Convery, 2021: 3), which depends on complementary policies and actions elsewhere.

Developing or having access to a proper innovation ecosystem is key to advancing innovation at the scale and speed required. A proper innovation ecosystem is made up of 
institutions, incentives, investments, information and cultural impulses: multiple factors that must be accurately combined if we are to reduce costs enough so that innovation does not remain 'an interesting anecdote' but becomes a 'transformative event' (Convery, 2021: 18).

The paper by Fitzgerald and Mason (2021), entitled 'Understanding productivity effects of hydraulic fracturing in unconventional natural gas deposits and implications for adoption in the developing world' complements the conceptual analysis developed by Convery (2021) by discussing a specific (and much debated) technological innovation: hydraulic fracturing (HF). So far, the latter has not been used much in developing countries, although they hold most current proven reserves of unconventional resources. Two main reasons can explain this limited adoption: first, the high level of technological sophistication embodied in HF, and second, its potential environmental impacts, particularly in terms of water contamination. While the environmental concerns of the local populations need to be properly addressed, Fitzgerald and Mason (2021) also point out that HF may help developing countries shift from coal (currently still around 36 per cent of their primary energy) to natural gas, thereby lowering their greenhouse gases emissions while possibly supporting their economic growth. For this reason, it is important to assess the experience that developed countries have had so far with HF to derive useful lessons on whether and how to apply this technology in developing countries.

To this aim, Fitzgerald and Mason (2021) estimate the marginal productivity of HF using a large dataset that combines information on injectants used, toxicity of ingredients and production levels collected from wells in Wyoming. The experience in this state seems particularly important since it was the first one to require reporting of chemical injectants being used in the HF process, while allowing firms to withhold information when 'trade secrets' are involved. The analysis of Fitzgerald and Mason (2021) provides interesting insights on the evolution of firms' disclosure of ingredients and the trade-off between intellectual property rights and environmental protection, which can usefully inform decisions and future discussions on potential substitution between injectants that contaminate groundwater and more benign ones. I expect that their results will attract the readers' attention and will spur further debate on this controversial topic in the future.

\section{Emissions trading and companion policies in Europe and China}

In line with all the other papers in this special issue, the paper by Verde et al. (2021), entitled 'The EU ETS and its companion policies: any insight for China's ETS?' tries to derive lessons arising from the climate policy of developed countries that may be useful for developing economies. For this purpose, it concentrates on the European experience with its own Emissions Trading System (ETS) to identify relevant insights for China's ETS. Focusing on the EU ETS and China's ETS appears particularly important since the former (which started in 2005) is the cornerstone of the EU climate policy, while the latter (which just started in 2021) will be the largest ETS at the global level - surpassing and actually doubling the size of the EU ETS itself - and might become the blueprint for other ETSs in developing countries. As argued above, additional policies are needed on top of carbon pricing to achieve more ambitious targets. Therefore, Verde et al. (2021) examine the interactions between ETSs and companion policies, discussing both the theoretical aspects underlying their relationship and the empirical evidence deriving from the EU ETS experience so far. Despite the differences between the EU and China in terms of 
ETSs and policy mix, some important insights can be transferred from the European experience.

First, a proper balance is needed between policies supporting emissions abatement innovation and those supporting the adoption of abatement technologies. Second, only permanent adjustments to allowance supply can effectively raise carbon prices in case of large market surplus. Finally, unless allowance supply adjusts in response to companion policies, the latter do not actually produce additional abatement. This problem (the so-called 'waterbed effect') could emerge also in China. Indeed, although allowance supply automatically adjusts to the output levels of regulated firms in China's ETS (being a relative cap-and-trade system), it does not adjust automatically for policies that have a direct or indirect effect on regulated firms' emission efficiency. An aspect that should be carefully addressed to ensure the environmental effectiveness of China's ETS.

I am confident that the papers in this special issue may foster a debate in our profession and can offer readers 'a room with a view' on the ever-changing and multiple challenges that we must face in the years to come.

\section{References}

Arneth A, Denton F, Agus F, Elbehri A, Erb K, Osman Elasha B, Rahimi M, Rounsevell M, Spence A and Valentini R (2019) Framing and context. In Shukla PR, Skea J, Calvo Buendia E, Masson-Delmotte V, Pörtner H-O, Roberts DC, Zhai P, Slade R, Connors S, van Diemen R, Ferrat M, Haughey E, Luz S, Neogi S, Pathak M, Petzold J, Portugal Pereira J, Vyas P, Huntley E, Kissick K, Belkacemi M and Malley J (eds). Climate Change and Land: An IPCC Special Report on Climate Change, Desertification, Land Degradation, Sustainable Land Management, Food Security, and Greenhouse gas Fluxes in Terrestrial Ecosystems. Geneva: Intergovernmental Panel on Climate Change (IPCC), pp. 77-129.

Brock W and Xepapadeas A (2020) Regional climate policy under deep uncertainty: robust control and distributional concerns. Environment and Development Economics, 1-28. https://doi.org/10.1017/ S1355770X20000248

Burke J, Byrnes R and Fankhauser S (2019) How to price carbon to reach net-zero emissions in the UK. Policy Report. Grantham Research Institute on Climate Change and the Environment and Centre for Climate Change Economics and Policy, London School of Economics and Political Science, London.

Convery FJ (2021) Carbon-reducing innovation as the essential policy frontier - towards finding the ways that work. Environment and Development Economics, 1-20. https://doi.org/10.1017/S1355770X20000467

Fitzgerald T and Mason CF (2021) Understanding productivity effects of hydraulic fracturing in unconventional natural gas deposits and implications for adoption in the developing world. Environment and Development Economics, 1-21. https://doi.org/10.1017/S1355770X20000534

Labeaga JM, Labandeira X and López-Otero X (2020) Energy taxation, subsidy removal and poverty in Mexico. Environment and Development Economics, 1-22. https://doi.org/10.1017/S1355770X20000364

Rogelj J, den Elzen M, Höhne N, Fransen T, Fekete H, Winkler H, Schaeffer R, Sha F, Riahi K and Meinshausen M (2016) Paris Agreement climate proposals need a boost to keep warming well below $2^{\circ} \mathrm{C}$. Nature 534, 631-639. https://doi.org/10.1038/nature18307

Rogelj J, Shindell D, Jiang K, Fifita S, Forster P, Ginzburg V, Handa C, Kheshgi H, Kobayashi S, Kriegler E, Mundaca L, Séférian R and Vilariño MV (2018) Mitigation pathways compatible with $1.5^{\circ} \mathrm{C}$ in the context of sustainable development. In Masson-Delmotte V, Zhai P, Pörtner H-O, Roberts D, Skea J, Shukla PR, Pirani A, Moufouma-Okia W, Péan C, Pidcock R, Connors S, Matthews JBR, Chen Y, Zhou X, Gomis MI, Lonnoy E, Maycock T, Tignor M and Waterfield T (eds) Global Warming of $1.5^{\circ}$ C. An IPCC Special Report on the Impacts of Global Warming of $1.5^{\circ} \mathrm{C}$ Above pre-Industrial Levels and Related Global Greenhouse gas Emission Pathways, in the Context of Strengthening the Global Response to the Threat of Climate Change, Sustainable Development and Efforts to Eradicate Poverty. Geneva: Intergovernmental Panel on Climate Change (IPCC), pp. 93-174. 
Verde SF, Acworth W, Kardish C and Borghesi S (2020) Achieving zero emissions under a cap-and-trade system. Florence School of Regulation, Policy Brief (2020/26), 1-14. https://doi.org/10.2870/343248

Verde SF, Galdi G, Alloisio I and Borghesi S (2021) The EU ETS and its companion policies: any insight for China's ETS?. Environment and Development Economics, 1-19. https://doi.org/10.1017/ S1355770X20000595

Cite this article: Borghesi S (2021). A room with a view: a special issue with a special perspective. Environment and Development Economics 26, 205-210. https://doi.org/10.1017/S1355770X21000103 